\title{
A Cross-Cultural Study of Some Selected Ghanaian and Foreign
}

\author{
Recipes \\ Isaac $\mathrm{Afful}^{1 *}$ \\ ${ }^{1}$ Department of English, University of Cape Coast, Cape Coast, Ghana \\ *Isaac Afful, E-mail: isaac.afful@stu.ucc.edu.gh/iafful8@gmail.com
}

\begin{abstract}
The focal aim of this study was to investigate the recipes as professional genres in Ghanaian and foreign contexts, in terms of their schematic structures and linguistic features. Using Swales' (1990) rhetorical approach to genre analysis, the study examined 20 recipes from well-known cookbooks. The analysis and discussion of the cross-cultural study pointed to three key findings. First, it was revealed that recipes are organised in six core moves. These are recipe title, serving details, ingredients list, methods, serving suggestions and additional notes. While additional notes and nutritional value per serving were frequently used in foreign recipes, they rarely occurred in Ghanaian recipes. Second, in terms of the textual space allocated to each move, the study revealed that the method was allocated much textual space (44.7\%) whereas the recipe title was allotted the least textual space (1.1\%). Third, as regards the lexico-grammatical features, it was revealed that the dominant lexico-grammatical feature in recipes from both data sets was imperative verbs. The study contributes to the genre theory and serves as an impetus for further research.
\end{abstract}

\section{Keywords}

genre, recipes, cross-cultural discourse, moves

\section{Introduction}

Following the seminal work of Swales (1990), genres, over the last few two decades have been studied in both academic and professional domains. The Genre theory, which emerges from a variety of perspectives ranging from academic, professional and more generally social contexts, seems to have a common paradigm, a coherent methodology and an overlapping concern with application. Originally a term used in classical times, the term "genre" has been defined from different perspectives in various disciplines. It was first used to refer to the kinds or types of literary pieces written in the field of literary studies. Genre has also been used in the music and dance fields in referring to text forms such as reggae, classic, hip-pop and blues. So widespread has the term become in Language studies that a sub-discipline is allocated for Genre Studies. As Bhatia points out, "the concept of genre, which had been so prevalent in literature, sociology and rhetoric for a long time, has started assuming importance in linguistics only recently” (Bhatia, 1993, p. 11).

Academic genres which have caught the curious eyes of applied linguists, over the last two decades 
include, abstracts (e.g., Santos, 1996; Stotesbury, 2003), acknowledgement sections (e.g., Hyland \& Tse, 2004; Cheng, 2012), results (e.g., Brett, 1988), discussions (e.g., Holmes, 1997) and conclusion (e.g., Yang and Allison, 2003). In the last decade, professional or non-academic genres in professional industries have received much scholarly attention. One of these settings is the food industry. As Ikas (n.d), cited in Klenova (2010) observes, "Indeed, a curious and pervasive interest in everything related to food, food preparation, food representation, recipe books, culinary culture, nourishment etc., has emerged in contemporary life within the last decades (pp. 411-415)”. As Klenova (2010) points out, Culinary Arts and Meal Science (CAMS) basically aim to unify craft, artistry and science in research and development of the meal in different situations, taking into account the whole meal atmosphere. A plethora of studies have also been carried out on domestic and familial genres. Such studies include parent-child talks (Chiswick et al., 2004; Lester, 2012; Lewis \& Gregory, 2013); Shopping list (Mahaltra \& Krishnan, 2012) and recipes (Karlin, 1988; Bender, 1999; Lin et al., 2002; Bloom, 2004; Klenova, 2010; Kohler, 2011). However, most of these studies were conducted outside Africa and by experts who were mainly concerned about food writing in general. Besides, I have not come across any study that paid much attention to the moves and lexico-grammatical features that typify the recipe as a genre. This study therefore seeks to fill the lacuna created by examining some selected Ghanaian and foreign food recipes, from a cross-cultural perspective, paying attention to their communicative function, schematic structures and lexico-grammatical features of the recipe as a genre.

\subsection{Research Questions}

The following research questions underpinned the study:

1) What communicative functions and moves typify Ghanaian and foreign recipes?

2) What lexico-grammatical features characterize Ghanaian and foreign recipes?

3) How different or similar are Ghanaian recipes from foreign recipes in terms of move structure and linguistic features that depict these genres?

The study employed the genre theory. The tenets of the genre theory are discussed in the section that follows.

\subsection{Genre Theory}

In this section, I aim to establish a theoretical framework for the present study by reviewing different traditions of genre studies and relevant research. Rather than seeing these different schools of genre as being contradictory, I consider them to be complimentary. Genre is not a clear-cut construct. Indeed, there have been different traditions which have interpreted and researched into genres. Sarcastically, Johns et al. (2006) notes, "If genre scholars across disciplines share one point of agreement, it is the complexity of genres (p. 248)”. According to Hyon (1996), three genre perspectives-Australian (or Sydney) School, North American New Rhetoric studies, and English for Specific Purposes—have been most productive in theorizing, researching, and offering pedagogical applications of genre theory. These perspectives are summarized in Table 1 below: 
Table 1. Synopsis of the Three Schools of Genre (Adapted from Hyland, 2004, p. 50)

\begin{tabular}{|c|c|c|c|c|c|}
\hline Orientation & Definition & $\begin{array}{l}\text { Intellectual } \\
\text { Roots }\end{array}$ & $\begin{array}{l}\text { Primary } \\
\text { Focus }\end{array}$ & $\begin{array}{l}\text { Educational } \\
\text { Contexts }\end{array}$ & $\begin{array}{l}\text { Sample } \\
\text { Genres }\end{array}$ \\
\hline Sydney & $\begin{array}{l}\text { Staged, } \\
\text { goal-oriented } \\
\text { social process }\end{array}$ & SFL & $\begin{array}{l}\text { Discourse } \\
\text { structure and } \\
\text { features }\end{array}$ & $\begin{array}{l}\text { L1 schools, } \\
\text { adult migrants }\end{array}$ & $\begin{array}{l}\text { Report, } \\
\text { recount, } \\
\text { narrative }\end{array}$ \\
\hline NR & $\begin{array}{l}\text { Recurrent social } \\
\text { action in } \\
\text { response to } \\
\text { situated context }\end{array}$ & Post-modernism & $\begin{array}{l}\text { Social } \\
\text { purposes, } \\
\text { context }\end{array}$ & $\begin{array}{l}\text { L1 university } \\
\text { composition }\end{array}$ & $\begin{array}{l}\text { Research } \\
\text { report, } \\
\text { patent, } \\
\text { medical } \\
\text { record }\end{array}$ \\
\hline ESP & $\begin{array}{l}\text { Class of } \\
\text { communicative } \\
\text { events } \\
\text { exhibiting } \\
\text { patterns of } \\
\text { similarity }\end{array}$ & SFL, Swales & $\begin{array}{l}\text { Discourse } \\
\text { structure and } \\
\text { features }\end{array}$ & $\begin{array}{l}\text { L2 and } \\
\text { professional } \\
\text { training }\end{array}$ & $\begin{array}{l}\text { Research } \\
\text { article, sales } \\
\text { letter, } \\
\text { academic } \\
\text { lecture }\end{array}$ \\
\hline
\end{tabular}

The ESP approach, which is more linguistic oriented than the other two approaches, was championed by Swales (1990) and Bhatia (1993). The ESP approach aims at helping L2 English users for speaking and writing in academic and professional settings. That is to say that the English for Specific Purposes (ESP) researchers are interested in genres as both an analytic and a pedagogical tool. According to Swales (1990, p. 58), “A genre comprises a class of communicative events, the members of which share some set of communicative purposes. These purposes are recognized by the expert members of the parent discourse community, and thereby constitute the rationale for the genre. This rationale shapes the schematic structure of the discourse and influences and constrains choice of content and style. Communicative purpose is both a privileged criterion and one that operates to keep the scope of a genre as here conceived focused on comparable rhetorical action. In addition to purpose, exemplars of a genre exhibit various patterns of similarity in terms of structure, style, content and intended audience. If all high probability expectations are realized, the example will be viewed as prototypical by the parent discourse community. The genre names inherited and produced by discourse communities and imported by others constitute valuable ethnographic communication, but typically need further validation". Some key issues stem out from this definition. First, genres vary, and manipulating them is possible, but they are nevertheless identifiable by a discourse community (Swales, 1990). Second, the definition presents genres as recognizable by members of a discourse community due to their (genres) prototypical schematic structure, or the most typical realization of the patterns of the events (Bhatia, 
1993; Swales, 1990). Third, the definition points out that these schematic structures are developed through a sequence of rhetorical moves (and component "steps") and the linguistic features that realize these moves. Next, each rhetorical move is a "bounded communicative act that is designed to achieve one main communicative objective” (Swales \& Feak, 2000, p. 35). Further, while a move can differ in length and size from one sentence (or utterance) to several paragraphs (or utterances), it generally contains one proposition. The sequences of moves represent the schematic structure of a genre in accomplishing deliberate social actions and to the coherent understanding of the discourse. Finally, the definition indicates that a text, whether spoken or written, must have certain features present for the discourse to be an exemplar of that particular genre. Swales (2004) however cautions that though genres are dynamic and open to change, they are not anything goes (Swales, 2004). The similarity between the ESP tradition and the Sydney School perspective of genre analysis lies in the fact that researchers in both traditions mostly examine and detail the formal (linguistic and rhetorical) properties of genres (Hyon, 1996). Hyland (2002) however draws a distinction between the ESP and the Sydney School and is of the view that unlike the Sydney School, ESP does not see genres as linguistic strategies for achieving general rhetorical goals in a culture. Rather, because ESP views discourse communities and their genres as being closely linked, genres are considered the property of particular communities rather than the culture at large.

The second school of thought on the concept of genre is the American New Rhetoric view. This was championed by scholars such as Miller (1984) and Bazerman (1988). These scholars emphasize genres as a social action. Miller, for instance, conceptualizes genre as a rhetorical action based on recurrent situations and for an open principle of genre classification based on rhetorical practice, rather than a closed one based solely on structure, substance, or aim (Miller, 1984). Miller (1984) argues, that a rhetorically sound definition of genre must be centered not on the substance or the form of discourse but on the action it is used to accomplish. Hyon (1996) draws a relationship between the New Rhetoric perspectives and the Australian school and posits that while similar to the Sydney School in their attention to the context of situation, the New Rhetoric perspective of genres is less focused on the linguistic features of genres and more concerned with the situated contexts in which genres are produced and used. In this sense, genres connote more than typical forms of utterances; they are recurrent, situated, and social actions that constantly evolve in response to situated contexts (Miller, 1984). Genres that have been investigated using from the American tradition of genre include scientific research reports (Bazerman, 1988), documents produced by tax accountants (Devitt, 1991), texts produced at a central bank in Canada (Smart, 1993), student and professional writing in finance (Freedman, Adam, \& Smart, 1994), and writing assignments at university (Molle \& Prior, 2008). The third orientation is based on Halliday's (1994) SFL, known in the US as the "Sydney School". For the Australian (SFL) genre analysts, genres are defined as staged, goal-oriented, and purposeful social processes in getting things done through language (Martin et al., 1987). In other words, genres are purposeful social processes because members of a culture purposefully interact to achieve them. They Published by SCHOLINK INC. 
are also goal-oriented because they get things done and finally, they are staged because multiple steps are taken to achieve particular goals. Rather than describing language in grammatical terms, SFL uses functional categories, and it regards meaning-making as the primary purpose of language. SFL is based on four major assumptions about language: (1) language use is functional; (2) the function is meaning-making; (3) the social context influences meaning; and (4) the use of language is a social semiotic process in which language users construct meaning by making certain linguistic choices within a given social context. According to Eggins (1994), a particularly distinctive feature of the Sydney School's approach to genre analysis is that its purpose is to construct both a theory of and analytical tools for investigating language as a social process, which in turn allows for comprehensive, specific, and systematic descriptions of linguistic patterns.

As Hyland (2004) reminds us, the three genre perspectives view language as a primary aspect of human behavior, and rather than being an instrument for the transmission of ideas, it is believed that "language, through genre, helps construct meaning and social context” (p. 50). The traditions however differ in terms of their definitions, intellectual frameworks, primary foci, and educational/professional contexts; however, they share a common goal: to analyze the relationship of genres to various contexts and to teach students how to act meaningfully in specific contexts (Hyland, 2004), and as such, I find the three perspectives as complimentary to one another.

The genre theory sheds some light on the present study in the sense that this paper investigates a genre that is usually encountered in professional and domestic environs-the recipe text. The study seeks to establish how the recipe text is organised in terms of moves, how these moves are sequenced, how much space is given to each move and what lexical and grammatical resources typify these recipes. Like other genres, the recipe is considered as a genre with a defined communicative purpose that is instructional (giving instructions on the preparation of a dish). Recipes, as social practices, also occur in the discourse community. In this very sense, the professional community comprises cooks and chefs who use recipes in their professional capacities. However, non-professional members such as students or housewives also make use of recipes. As social practices, recipes conform to the norms and practices of the discourse community in which they are found. As would be seen in this paper, recipes have a conventionalized internal structure that typifies them as genres or institutional templates.

Having discussed the theoretical lens of the study, I shall proceed to review some empirical studies on recipes. As Klenova (2010) notes, over the years, recipes have been discussed predominantly under the designation of genre and register. Empirical studies done on recipes have evolved from syntactic and semantic analysis to analyses from the sociolinguistic, pragmatics and discourse perspectives.

Karlin (1998), for instance, investigates the semantics of verbs, tense and aspects used in cookbooks. The data comprised phrases and sentences containing verbal modifiers selected from nine different cookbooks. Using a quantitative analysis, the discussion of the data pointed to some key findings. It was revealed that the adverbials were used to show culmination and this was dominantly achieved through the use of cardinal count adverbials such as once as in in Stir once and add collard sauce. It Published by SCHOLINK INC. 
was also revealed that verbal modals in recipes denote the sense of duration of an action. This is realized by the use of explicit duration in time units as in Bake in a preheated oven for 30-60 mins and in duration that is co-extensive with the duration of another action as seen in this example: Continue to cook while gently folding the cheeses with spatula. Finally, it was also revealed that these verbs could denote an end result as in Break it up as finely as possible, denote location of an action as in Cut from head to toe, show the usage of an instrument as in Cut with a pastry cutter or denote speed as in Stir very gradually and with swift strokes. Despite the well-organized nature of the article, the study did not justify the choice of its samples. Karlin also fails to report in what accounts for the variations in meaning.

A year later, Bender’s (1999) major work on recipes, using the competence theory of syntax, focused on the occurrence of the null objects in English recipes. This study was hinged on the hypothesis that English recipes do not allow zero realization of object NPs. Using Culy's (1996) VARBULL analysis as its framework, the study sampled 50 recipes taken from 5 cookbooks from well-known restaurants in the Britain. The study revealed that null objects occur frequently in English recipes. This assertion is instantiated in examples such as Season_ with salt; Bake _ until golden brown; Allow _ to cool and Dry _with clean towel before you defry _. He opines that "while null objects are unacceptable in decontextualized sentences usually studied by linguists, they are more common in recipes (1999, p. 14)". It was also revealed that the possibility of null objects in recipes appear to be restricted with verbs than with prepositions as found in Massam (1998). One major conclusion of this study was that the language of recipes has social value as the language usage identifies a writer as one in authority. This study was well-balanced as it looked at both the theoretical and sociolinguistic implications of the occurrence of null objects in recipes.

As earlier mentioned, the literature indicates that there has been an evolution from studies based on traditional linguistics to more practical or applied studies of recipes as they are used in the discourse community. Mention can be made of Lin et al.'s (2002) move analysis on recipes. Their study investigated the style variations in food recipes. Their corpora comprised recipes from two authors in a cookbook and from an amateur recipe from the internet. The study revealed that there are variations in the steps of the recipes. Thus, a first step in one recipe can become the seventh step in another recipe of the same dish (fish pies). At the sentential level, the study also revealed that there were variations that occurred in the sentence structuring. There was also variation at what he calls the "recipe level" where recipe writers prefer the use of certain lexical words to the other. For instance, whereas a recipe could have a step as "Put the oven on", other writers could have the same step realized as "Preheat the oven"; "Heat the oven" or "Switch on the oven". Skipping objects were also identified as typical of recipes. This collaborates with Bender's (1999) finding of the null object in recipes. Lin et al also argue that recipe writers tend to establish their own idiolects and hence, the existence of the variations. Finally, the study revealed that the variation in these choices have socio-pragmatic implications.

Hung's (n.d.) major study tests the potency of using a genre based pedagogy in teaching recipe writing Published by SCHOLINK INC. 
to final year students in high school. Hung taught her students how to write recipes using both the process pedagogy and the genre based pedagogy. She did this to compare the effects of these approaches in her students' writings. The study revealed that students were able to write more effectively when she used the genre-based approach. The recipes written by the students had clearly stated aims, proper sequencing of headings, specific technical terms and the right measuring symbols for the ingredients were stated. However, the study appeared to be ill-balanced as it was more pedagogical than genre-based. Consequently, the study did not focus much on the moves, steps and lexico-grammatical features of the recipe genre.

Using Swedish classic baking cookbooks as the data source, Kohler (2011) investigates how cultural specific features such as ingredients, measurements and etymology of the names of dishes in cookbooks are handled when translated into a language where different measurements and ingredients are the norms. The study revealed that such writers use the replacement and retention strategy where the original measurements of the ingredients remain the same in the target language while conversions and names of dishes are stated in parenthesis. The study also identified cultural-specific names of the dishes used in English. Despite this study being very informative, it appears it would have been more revealing if the study had focused on how translations in recipes are realized in two very different cultures like Japan (being an Asian country) and English.

The review of the literature indicates that studies on recipes have evolved from concentrating on core aspects of language study such as Grammar and Semantics (Karlin, 1988; Bender, 1999) to practical studies on recipes used in a socio-cultural context (Lin et al., 2002; Kohler, 2011). While some studies are more interested in pedagogical issues (Hung, 2003), others have focused on multi-cultural studies (Kohler, 2011). It is observed that few empirical works have focused on genre studies (Klenova, 2010). Most of these studies however were more interested in the moves of the recipe genre. Such studies also concentrated on recipes within the European community. Consequently, fewer studies have looked at non-European or African recipes. This study, a cross-cultural one, thus seeks to examine the communicative purpose, moves (paying attention to their frequencies, sequencing and textual space) and the linguistic features that typify both Ghanaian recipes and foreign recipes as distinct genres.

\section{Method}

The study employed a qualitative study design. The design helped me to understand the processes, characteristics and organizational aspects of the documents as social products in their own right as well as what they claim to represent (Creswell, 1994). However, the study also made some minimal references to some descriptive statistics such as frequency counts and percentages in analyzing the data. The data used for the study were 20 purposively-sampled recipe texts, comprising 10 Ghanaian recipes and 10 foreign recipes. These recipes were Ghanaian soup recipes (hereafter, GSP), foreign soup recipes (hereafter, FSP), Ghanaian snack recipes (hereafter, GSK) and foreign snacks recipes (hereafter, FSK). A total number of 30 Ghanaian recipes constituted the study's population and out of that, 10 
recipes were purposely sampled for the study... The study adopted a cross-cultural ESP genre analytical approach (Swales, 1990) in analyzing the data... This was appropriate as it enabled me to identify the moves or the schematic structure present, as well as the lexico-grammatical features pervasive in both samples. In effect, what informed my choice of this model is on the basis of appropriateness and suitability.

The analysis was done in relation to the research questions that underpin the study. I first identified the schematic structure or the moves that were present in the genre, using blocks of meanings each section of the text seemed to convey. This is against the backdrop that moves are units of meaning in a text and hence, one needs to identify them based on what purpose or function these semantic units play in the text. As swales and Feak (2004) observes, while a move can vary in length and size from one sentence (or utterance) to several paragraphs (or utterances), it generally contains one proposition. I also sought the views of other student researchers to know whether they agree to the moves identified or otherwise. The inter-rater reliability test recorded $80 \%$ agreement on the moves. The moves were then labeled and their frequencies were recorded. Again, I took note of the sequencing and textual space allocated to the moves. Here, I was interested in the number of words allocated to the moves. The next phase of the analysis was to identify the lexico-grammatical features that characterized the genre.

\section{Results and Discussion}

\subsection{Schematic Structures and Lexico-Grammatical Features Identified from the Sample}

The overarching communicative purpose of recipes is to provide a step-by-step process or instructions to be followed in preparing a particular meal or dish (Kowtaluk, 1982). Thus, recipes are functionally instructional genres. The purpose of recipes is achieved through various moves and steps. The data revealed that recipes are organized into the following six moves and steps.

Move 1: Recipe Title/Caption

Move 2: Serving Details

Step 2a: Number of People Served

Step 2b: Nutritional Value per Serving

Move 3: Ingredients List

Step 3a: Core Ingredients

Step 3b: Optional Ingredients

Move 4: Methods

Step 4a: Methods for Preparation of Recipe

Step 4b: Methods of Seasoning Recipe

Move 5: Serving Suggestion

Move 6: Additional Notes

These moves are discussed in the subsequent paragraphs. 


\subsubsection{Recipe Title}

The first core move was the recipe title. The titles of the recipe performed identification or labeling functions; they were aimed at identifying the meal type and orienting readers as to what they should expect to be cooked. Considering that the recipe texts were contained in cook books, it is expected that the titles of the recipe were meant to guide the reader in deciding what kind of meal s/he wants to cook. As Senda and Sinohara (2000) note, a title is the first point that captures the reader's eye, "the point from which he may decide whether a text is worth reading or not” (Haggan, 2004, p. 23). For Swales and Feak (1994), an appropriate title should be self-explanatory and yet informative. As expected, the titles in the Ghanaian recipes were captioned in a Ghanaian Language with their translation equivalents in English. This confirms Kohler's (2011) study about translation equivalencies in cross-cultural recipes. The titles in both Ghanaian and the foreign recipes did not show any significant difference. Examples of such titles include:

1) $\mathrm{Ab}[$ nkwan (Palmnut soup)(GSP)

2) Fetri-Detsi (Okro soup- Ewe style)(GSP)

3) Abelemamu (Roasted Cornmeal)

4) Agbelikaklo (Cassava Cakes) (GSK)

Concerning the linguistic resources used in constructing the titles, the data set revealed, quite unsurprisingly, that the titles were nominal, comprising simple nouns and noun phrases. The table below illustrates this assertion:

Table 2. Realizations of the Titles in Ghanaian and Foreign Recipes

\begin{tabular}{llll}
\hline \multicolumn{2}{c}{ GHANAIAN RECIPES } & \multicolumn{2}{c}{ FOREIGN RECIPES } \\
NOUNS & NOUNS & NOUNS & NOUN PHRASES \\
\hline Nkrakra (Plain soup/ & Fetri-Detsi (Okro & Gazpacho (Chilled & Cannery Row Soup \\
Pepper soup) (GSP) & Soup- Ewe Style) (GSP & tomato soup) (FSP) & (FSP) \\
Abelemamu (Roasted & & & Meatball Soup (FSP) \\
Cornmeal) (GSK & & \\
Kaklo (Plantain and & & Eggplant Pie (FSK) \\
Corndough) (GSK) & & \\
Agbelikaklo (Cassava & & Spanish Omelette \\
Cakes) (GSK) & & (FSK) \\
& & Almond Cookies (FSK) \\
\hline
\end{tabular}

Concerning the sequencing of the moves, it was realised that the recipe title occurred as the first move in all twenty recipes. The length of the titles ranged between one to three words in both sets of data. Due to their conciseness, the recipe titles were allocated the least textual space (see Figure 1). 


\subsubsection{Serving Details}

The second core move identified from the data set was Serving Details. It occurred in all 20 samples of the recipes. The move was realised in two steps. First is the number of serving and second is the nutritional value per serving. The communicative purpose of this move is to give an estimated number of people who could be served at a sitting with the meal and the nutritional value per serving. Perhaps, this is to guide the cook or chef to avoid wastages of the meal. That is to say that, if the cook is going to serve a larger number than what is stated in the recipe, s/he can modify the quantity or proportions of ingredients to achieve that goal.

The number of serving per meal ranged from 2 to 12 depending on the type of meal. This step was evident in both data sets. Turning to the linguistic features, it was realised that the number of serving was typified by expression or was introduced by the adjective phrase, "Enough for + (number of people that can be served at a sitting)". Others were introduced by the verb, "Serves/yields + (number of people to be served at a sitting)". In the foreign recipes, they were introduced by noun, "Servings". This form (servings) was however absent in the Ghanaian recipes. The number of serving for the soup recipes ranged between 6 and 16 while those from the snack recipes (for instance, fried yam, yam balls and spring rolls) ranged between 2 and 6 . This could be due to the fact that unlike snacks which are relatively easier to prepare, preparing soups is time-consuming and hence at a sitting, a soup meal can serve a larger family, especially in the African context. Examples of this move from the data set include:
1) Fetri-Detsi
Enough for 6 people
(GSP)
2) Minestrone Soup
Yield:16 servings
3) Spanish Omelette
4 servings
4) Abelemaamu (Roasted cornmeal)
Enough for 2 people
(GSK)

The second step under the serving details move was the nutritional value per serving. Per the data set, the nutritional value occurred in the foreign recipes and in cookbooks that are concerned with healthy lifestyle or keeping fit. This is especially helpful to those who are allergic or have been advised by their doctors not to take too much of a particular food nutrient. In this step, writers of these recipes provide the amount, quantity or value of food nutrients contained in the recipe that is being discussed. As Klenova (2010) notes, the food's calorific content is typically measured and usually stated in the form of the approximate number of calories or joules contained per serving. Nutritional information includes the numbers of grams of protein, fat, and carbohydrates per serving along with the vitamin content.

On the whole, in terms of sequencing, it was revealed that a majority of the Serving details move come after the recipe title.

\subsubsection{Ingredient List}

The third core move was the ingredient list. It occurred in all 20 samples of the recipes. The ingredient list presents the different food items one uses when cooking a particular dish. From the data set, it was realised that the move had two steps. The first step presented ingredients that were obligatory to be Published by SCHOLINK INC. 
used in preparing the dish while the second step embodied ingredients that were secondarily or optionally used in preparing the dish (González, 2004). The core ingredients for the snack recipes include sugar, nutmeg, milk, cooking oil, flour and dough while those for the soup recipes include water, onions, tomatoes, peas, beans and fish. Sometimes, the ingredients are listed in the order in which they are needed, which are required for the preparation of the dish. Again, the ingredients are more often than not, presented with their quantities and/or proportions that correspond to the number of servings (if these are specified).

It is interesting to note that some lexico-grammatical features characterise the ingredient lists. The move was dominated by registers that are concerned with units of measurements. Examples of the measuring units identified are:

- $\quad 2$ cups of groundnut paste (GSK)

- $\quad 80 \mathbf{g}\left({ }^{3} / 4\right.$ cups) of raw shredded almonds (FSK)

- 1 oz of yeast (FSK);

- $\quad 1 / 2$ tsp. vanilla essence (GSK);

- $\quad 1 \mathrm{lb}$. beef and $1 / 2 \mathrm{lb}$. mutton (GSP)

- 1 clove garlic, minced (FSP)

- 4 pt. deep sea water (GSP).

There was also the dominance of simple and complex adjectives. The simple adjectives included adjectives associated with colours or those that appeal to our senses, such as sweetened, bright, powdered, fine, red, green and descriptive words such as large, smoked, chopped, grated, little, dried, roasted, and boiled. The compound adjectives, mostly hyphenated, included adjectives such as medium-sized, well-beaten, sun-ripened, over-ripped and non-fat.

It can be posited that since recipe genres are instructional, the use of these adjectives and accurate units of measurement are made so that the desired results or meal is turned out after the meal is prepared. It must also be mentioned that unlike the other moves, the ingredient lists was centered in the text and they were thus captured in different font styles. Perhaps, these artistic effects are done to ensure that the move is easily identified so that the cook does not overlook such an important schematic unit as the ingredient list in the recipe.

\subsubsection{Methods}

The fourth core move was the methods, occurring in all 20 recipe samples. This move spelt out the steps, procedures and processes the cook needs to follow in preparing and seasoning the dish. This move, in the Ghanaian recipes, had two steps. The first step dealt with the methods associated with the preparation of the main dish. The second step involved the methods used in the seasoning of the meal. Pictures and other visuals of how the recipe is to be prepared were also evident in the methods.

It must be noted that the methods move in both data set occupied the largest textual space in the data set (between 90-100 words for soup recipes and 30-50 word for snacks).

Concerning the lexico-grammatical features identified, it was revealed that recipes make use of Published by SCHOLINK INC. 
imperatives which were usually process verbs captured in present tenses. As imperatives, the verbs were in the base form with an implied subject (you). The use of imperatives is suggestive that recipes are instructional and hence, it connotes the idea that for one to get the desired results, one needs to follow the steps given in the recipe, doggedly. The verbs also had varying semantic meanings relating to verbs of cooking, cleaning, and cutting, seasoning and adding to the food. Examples of these process verbs from the corpus are illustrated in the Table below:

Table 3. Various Semantic Distinctions of Verbs in Recipes

\begin{tabular}{|c|c|c|c|c|c|}
\hline $\begin{array}{l}\text { Verbs related } \\
\text { to cooking }\end{array}$ & $\begin{array}{l}\text { Verbs related } \\
\text { to cleaning }\end{array}$ & $\begin{array}{l}\text { Verbs related } \\
\text { to cutting }\end{array}$ & $\begin{array}{l}\text { Verbs related } \\
\text { to seasoning }\end{array}$ & $\begin{array}{l}\text { Verbs related } \\
\text { to adding to } \\
\text { the dish }\end{array}$ & $\begin{array}{l}\text { Verbs } \\
\text { related to } \\
\text { shaping of } \\
\text { food }\end{array}$ \\
\hline $\begin{array}{l}\text { Heat, scald, } \\
\text { sauté, stir-fry, } \\
\text { simmer, boil, } \\
\text { fry, grind, } \\
\text { roast }\end{array}$ & $\begin{array}{l}\text { Rinse, wash, } \\
\text { drain, strain, } \\
\text { break, sieve }\end{array}$ & $\begin{array}{l}\text { Chop, peel, } \\
\text { crush, mash, } \\
\text { shred, crack, } \\
\text { trim off, slice, } \\
\text { grind }\end{array}$ & $\begin{array}{l}\text { Season, } \\
\text { marinate, } \\
\text { dissolve, }\end{array}$ & $\begin{array}{l}\text { Pour, } \quad \text { add, } \\
\text { sprinkle, stir, } \\
\text { mix, }\end{array}$ & $\begin{array}{l}\text { Roll } \\
\text { shape }\end{array}$ \\
\hline
\end{tabular}

Some of these verbs were contextually used. That is to say that some were exclusively used for the Ghanaian soup (SPV) and snack recipes (SNV) while others were also solely used for the foreign recipes. Table 3 below presents the variation in the use of the verbs in both data sets:

Table 4. Cultural Differences Concerning the Use of Verbs in Recipes

\begin{tabular}{llll}
\hline GHANAIAN RECIPES & FOREIGN RECIPES \\
SPV & SNV & SPV & SNV \\
\hline Parboil, grind, season, & Sieve, rub, scrub, twist, & Blend, sprinkle, steam, Chop, beat, soak, \\
squeeze, pound, reduce, & grate, roast, cool, & garnish, chill, sauté, steam, stir-fry, roll \\
strain & pound & marinate, scald, shred
\end{tabular}

Verbs such as wash, cut, clean, heat, add, peel, mix and put were commonly used in both Ghanaian and foreign recipes.

Most of the verbs in both data sets were also transitive. Examples of such verbs are, cook, fry, put, mix, break, dissolve, stir and drain. However, some of the transitive verbs had elliptic or null objects and this finding corroborates those of Bender (1996) and Lin et al. (2002). Examples from the data set include the following: 
1) Cook ... for one hour (GSP)

2) Store ... in a clean container with lid in a dry place (GSK)

3) Cover ... and chill ... in the refrigerator for several hours. (FSP)

4) Fry ... in shallow fat and serve ... hot. (FSK)

It is seen that these objects though elliptic, had cataphoric references in the recipe text. That is, their objects had inferential meanings.

As regards the language used in the methods, it was seen that the vocabulary choices made here were clear, precise and evocative (Bloom, 2008). The use of the present tense of the verbs seems suggestive of the fact that cooking is viewed as a habitual activity that goes on in the domestic environs (Bloom, 2008). At the sentential level, most of the sentences were simple and compound sentences. The compound sentences also employed both syndetic and asyndetic coordinations. Examples are illustrated below:

1) Sieve corn into a basin. (Abelemaamu. GSK): Simple sentence

2) Remove them from the soup. (Fetri-detsi. GSP): Simple sentence

3) Soak the dried mushroom in the warm vegetable broth for 15 mins (FSK): Simple sentence

4) Boil till tomatoes are tender, remove, mash and return to soup (Nkatenkwan - GSP): Asyndetic coordinated sentence joined by commas

5) Bring to boil and add pastina. (Homemade Turkey Soup - FSP): Syndetic coordination

Again, there were very rare occasions where subordinate clauses occurred in both data sets. Perhaps, this is done to avoid all forms of ambiguity and complexity that could be associated with the meaning of the sentence. The use of simple and coordinated sentence therefore presents the methods clearer and direct to the cook. The similarities in both data sets teased out here go a long way to support the generic integrity of the recipe as a genre (Bhatia, 1993).

\subsubsection{Serving Suggestions}

The fifth core move is the serving suggestions. This move suggests to the cook some foods that could be best eaten with the prepared meal. It also provides information on how best the meal can be served. The serving suggestions move was evident both Ghanaian and foreign recipes. The move was realized in two forms. First, the move was mostly introduced by Serve with + (the proposed meal). This was typical of the Ghanaian recipes. Examples include:

6) Serve with yam fufu (Pepper soup, GSP)

7) Serve soup with fufu, boiled yam or rice (Groundnut soup, GSP)

Second, the move was also realized as Serve + (manner or degree adjunct). This occurred in both Ghanaian and foreign recipes. Examples include:

8) Serve hot (Chinese Noodles, FSK)

9) Serve at once or refrigerate for later reheating (Homemade Turkey Soup, FSP)

10) Serve as snack (GSK)

11) Serve hot with fufu, boiled yam or rice (Nkatenkwan, GSP)

Published by SCHOLINK INC. 


\subsubsection{Additional Notes}

The final move identified is the additional notes. It occurred twice in the Ghanaian recipes and occurred in almost all the foreign recipes in the data set. The additional notes are usually helpful tips, commentaries and notes that are aimed at providing definitions to some very technical terms, providing cautions, alternative methods of preparing the meal and general remarks. This move was introduced by the italicized word, Note in the Ghanaian recipes and by The Chef Suggests or Health Counsels in some of the foreign recipes. Examples are:

1) Note-If it is fresh fish, parboil the fish or steam a little with salt and onions. Use the stock to half-cook the palmnut juice as in soup above. Drop fish in gently and continue to cook gently until soup thickens(Palmnut soup, GSP).

2) Note-Koliko (fried cocoyam), duade (cassava) and atomo (sweet potato) can be fried, using the same method (Fried yam-GSK).

3) The Chef Suggests-This is an excellent dish to be taken when travelling or on an excursion because it can be eaten cold (Eggplant Pie, FSK).

4) Health Counsels-This typical Spanish dish is very appropriate for picnics and excursions. It supplies some calories and carbohydrates from potatoes, and high-quality protein from both eggs and potatoes. It also supplies Vitamins A, B, D and E. Those with a tendency to high levels of cholesterol or those prone to arteriosclerosis should be cautious when using this dish, as it is not recommendable for them to have more than two eggs a week. Children, adolescents, sportsmen and active persons in general can best tolerate eggs and take better advantage of their nutritional properties. As the main ingredients in Spanish Omelet are eggs and potatoes, which are easy to digest and assimilate, the dish is appropriate for those with a delicate digestive system, malnourished individuals, or people convalescing from weakening diseases or from surgery (Spanish Omelet, FSK).

\subsection{Frequency, Sequencing and Textual Spacing of Moves}

The bar chart below (Figure 1) presents the frequency distribution of the six moves identified in recipes. 


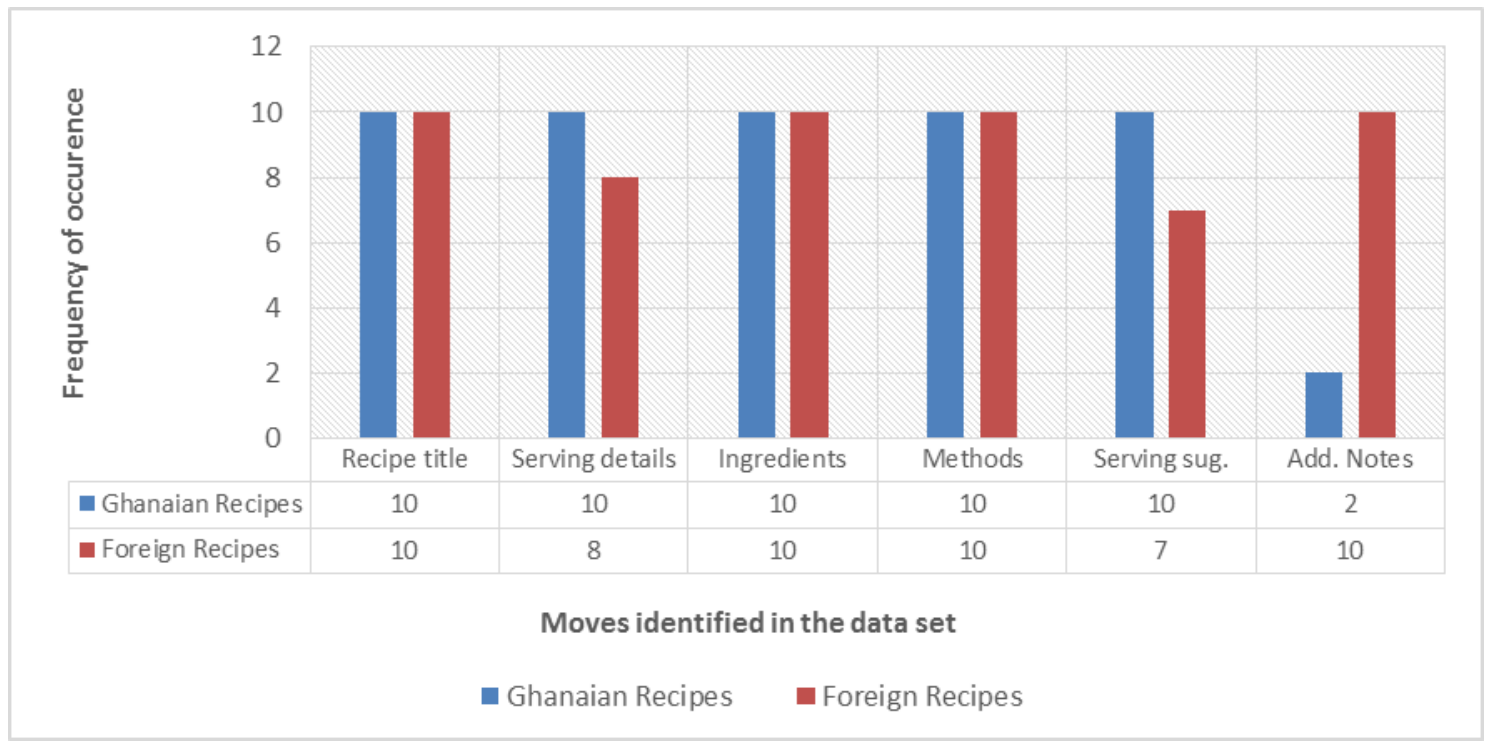

Figure 1. Frequency of Occurrence of Moves in Recipes

As can be seen from Figure 1, the recipe title, ingredients and methods recorded a 100\% occurrence. It is also observed that while the serving suggestions occurred in all 10 Ghanaian recipes, the move occurred only seven times in the foreign recipes. Similarly, there were variations in the occurrence of the additional notes move as far as Ghanaian recipes and foreign recipes are concerned. While it occurred five times in the latter, it was realised in all instances of the former. Additionally, serving details occurred 8 times in foreign recipes as against 10 in Ghanaian recipes. The fact that there was little variation in the frequencies of occurrence found in both data sets may suggest that this is a highly conventionalized and indeed static genre (McLaren \& Gurău, 2005; Jing et al., 2002). That there were some subtle variations across the genres is not surprising because Swales (2004) reminds us that "there are choices and constraints in genres and that genres are dynamic and open to change”.

Concerning sequencing, the data revealed that all of the moves in the Ghanaian recipes were sequenced in the following fixed order: 1 2 3 4 5. There were however few variations in the sequencing of

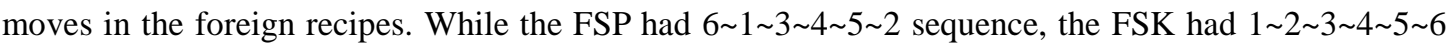
move patterning. Table 5 summarises the sequencing of moves in both data sets:

Table 5. Sequencing of Moves in Recipes

\begin{tabular}{ll}
\hline RECIPE & SEQUENCING OF MOVES \\
\hline Nkakra (Pepper Soup) & $1 \sim 2 \sim 3 \sim 4 \sim 5$ \\
Fetri-Detsi (Okro Soup- Ewe Style) & $1 \sim 2 \sim 3 \sim 4 \sim 5$ \\
NkateNkwan (Groundnut soup) & $1 \sim 2 \sim 3 \sim 4 \sim 5$ \\
Ab[ nkwan (Palmnut soup) & $1 \sim 2 \sim 3 \sim 4 \sim 5 \sim 6$ \\
Nkateb[ (Palmnut-groundnut soup) & $1 \sim 2 \sim 3 \sim 4 \sim 5$ \\
\hline
\end{tabular}




$\begin{array}{ll}\text { Y[I[ niashi(Fried Yam) } & 1 \sim 2 \sim 3 \sim 4 \sim 5 \sim 6 \\ \text { Togb[i (Doughnuts) } & 1 \sim 2 \sim 3 \sim 4 \sim 5 \\ \text { Abelemaamu (Roasted Cornmeal) } & 1 \sim 2 \sim 3 \sim 4 \sim 5 \\ \text { Agbelikaklo (Cassava Cakes) } & 1 \sim 2 \sim 3 \sim 4 \sim 5 \\ \text { Ats]m] (Twisted cakes) } & 1 \sim 2 \sim 3 \sim 4 \sim 5 \\ \text { Cannery Row Soup } & 1 \sim 6 \sim 3 \sim 4 \sim 5 \sim 2 \\ \text { Chilled Tomato Soup } & 1 \sim 6 \sim 3 \sim 4 \sim 2 \\ \text { Homemade Turkey Soup } & 1 \sim 6 \sim 3 \sim 4 \sim 5 \sim 2 \\ \text { Meatball Soup } & 1 \sim 6 \sim 3 \sim 2 \sim 4 \\ \text { Minestrone soup } & 1 \sim 6 \sim 3 \sim 4 \sim 2 \\ \text { Eggplant Pie } & 1 \sim 6 \sim 3 \sim 4 \sim 5 \\ \text { Chinese Noodles } & 1 \sim 6 \sim 2 \sim 3 \sim 4 \sim 5 \\ \text { Almond cakes } & 1 \sim 6 \sim 3 \sim 4 \\ \text { Spanish Omelette } & 1 \sim 6 \sim 2 \sim 3 \sim 4 \sim 5 \\ \text { Spring rolls } & 1 \sim 6 \sim 2 \sim 3 \sim 4 \sim 5\end{array}$

The sequencing of moves supports the ESP viewpoint of genres as formulaic texts despite few variations. Thus, it confirms the generic integrity of genres. As Bhatia (1993) citing Swales (1990) makes mention, various genresdisplay "constraints on allowable contributions in terms of their intent, positioning, form and functional value” (Bhatia, 1993). Bhatia explains the meaning of this part of Swales' definition by saying that although the writer has a lot of freedom to use linguistic resources in any way they like, they must conform to certain standard practices within the boundaries of a particular genre else the genre becomes odd. In this sense, despite that fact that writers of recipe texts have the linguistic freedom to choose from a pool of linguistic resources in constructing and structuring their recipe texts, they must conform to the accepted practices that characterize the recipe as a genre. This prevents the potential of their texts to become very odd or seen as total deviations. For Swales (1990), the sequences of moves represent the schematic structure of a genre in accomplishing deliberate social actions and to the coherent understanding of the discourse.

The textual space allocated to each move is also worth mentioning. This is based on the view in communication research that how much space given to a unit of text or a move is indicative of how important or valuable that information is. The textual space was calculated using word counts as the unit of analysis. A word in this light was considered as a grapheme or a combination of graphemes in a text usually separated orthographically, by a white space. It was revealed form from both data set that the methods move had more textual space being assigned to it in the recipe text (about 1,591 words) while the recipe title/caption had the least textual space allocated to it (39 words). Table 6 below gives a vivid illustration of the textual space given to each move. 
Table 6. Textual Space Allocation to Recipe Moves

\begin{tabular}{lcccc}
\hline Move type & $\begin{array}{c}\text { Ghanaian recipes } \\
\text { (word count) }\end{array}$ & $\begin{array}{c}\text { Foreign recipes } \\
\text { (word count) }\end{array}$ & \multicolumn{2}{c}{ Total number of textual } \\
space
\end{tabular}

That the methods was allocated much textual space goes to buttress the fact that recipes are basically instructional genres. Hence, one's failure to go according to the steps would lead one to dire consequences. As such, writers of these recipes in cookbooks devote much time and give much space to the methods to be followed in cooking a particular meal. This textual space of the methods is followed by Ingredients (25.6\%), additional notes (18.3\%), serving details (8.3\%), serving suggestions (2.0\%) and recipe title (1.1\%) in that descending order.

\section{Conclusion, Key Findings and Implications}

This study sought to do a cross-cultural study of the schematic structure and linguistic features of Ghanaian and foreign recipes. The study adopted Swales' (1990) generic approach in analyzing the recipes. Twenty recipes (comprising 10 Ghanaian and 10 foreign recipes) were sampled from three cookbooks. It is seen from the study that the communicative purpose of recipes is largely instructional than informative. It was again revealed that recipes are organized in six core moves: recipe title, serving details, ingredient lists, method, serving suggestion and additional note. The recipe titles in both Ghanaian and foreign recipes specified the name of the dish and they were concise in nature. The serving details comprised the number of people per serving for each meal and the nutritional value for the dish being prepared. The ingredient list and the methods were two significant moves. They had two steps each. The ingredient list comprised core ingredients and optional ingredients while the methods comprised methods for preparing the recipe and methods for food seasoning. The serving suggestions differed from the serving details in that they were very brief and they proposed how best the meal could be served. Finally, the additional notes provided vital yet optional background information on each meal. This final move rarely occurred in Ghanaian recipes but was dominant in the foreign recipes. Concerning the second research question which was to tease out the lexico-grammatical resources used in constructing the recipe genre, the study revealed that the recipe titles, across both data sets, were nominal in structure. The ingredient lists were also typified by simple and compound adjectives and 
specific registers reflected in the measuring units and specific cooking tools and equipment. In terms of format, the move was clearly distinct from the other moves. One key finding worth mentioning was that there was the dominant use of imperative mood, process verbs, null objects and coordination between and across sentences. Concerning the variation in the moves and linguistic features in the two data sets, it was revealed that there were few variations. While the sixth move, additional notes, was rarely used in Ghanaian recipes, it was very dominant in foreign recipes. Similarly, the Ghanaian recipes dominantly captured serving suggestions. Again, the foreign recipes often provided a down-to-earth analysis of the nutritional values of the meal to be cooked but this rarely occurred in the Ghanaian recipes. In terms of linguistic features, the study revealed that unlike Ghanaian recipes, foreign recipes usually employ compound sentences. In terms of textual space, it was revealed that due to the genre being very systematic, informative and instructional, the methods was allocated the largest textual space in both data set while the recipe titles were allocated the least textual space. While the method was captured in a total of 1,591words (representing 44.7\%), the recipe title was captured in 39 words (representing 1.1\%). Finally, in terms of sequencing, the Ghanaian recipes to a large extent, followed a systematic patterning of moves $(1 \sim 2 \sim 3 \sim 4 \sim 5)$ while the foreign recipes had varying sequence of moves.

The study makes significant contributions to theory, practice and future research. First, in terms of theory, the study contributes to the genre theory, especially from the ESP perspective. The genre theoryenabled me to identify six core moves with their steps and their distinct lexico-grammatical features as well as tease out the differences and similarities in terms of how two cultures organize their thoughts in writing. Such a study not only broadens our knowledge base about a less-researched genre like the recipe text, but also, it helps us to appreciate that the ESP approach to genre study is not only potent in analyzing academic genres but such an analysis is possible for professional and familial genres. Second, in terms of practice, this study gives inspiration to text construction. It could serve as a guide for anyone who is given the task to write a recipe. I believe the schematic structure and the lexico-grammatical features identified in this work will in no uncertain terms help novice recipe writers and professionals to construct good recipes. Finally, the study has implications for further research since there appear to be relatively less linguistic studies on the recipe genre, especially in an African setting.

\section{References}

Bazerman, C. (1988). Shaping written knowledge: The genre and activity of the experimental article in science. Madison, WI: University of Wisconsin Press.

Bender, E. (1999). Constituting contexts: Null objects in English recipes. Working Papers in Linguistics. Retrieved December 3, 2017, from http://www.ling.upenn.edu.papers/pwpl.html

Bhatia, V. (1993). Analyzing genre: Language use in professional settings. London: Longman.

Bloom, L. (2008). Food consuming. College English, 70(4), 346-360.

Published by SCHOLINK INC. 
Brett, P. (1994). A genre analysis of the results section of sociology articles. English for Specific Purposes, 13(1), 47-59. https://doi.org/10.1016/0889-4906(94)90024-8

Cheng, S. W. (2012). A contrastive study of master thesis acknowledgements by Taiwanese and North American students. Open Journal of Modern Linguistics, 2(1), 8-17. https://doi.org/10.4236/ojml.2012.21002

Chiswick, B., Yew, L. L., \& Miller, P. W. (2004). Parents and children talk: The family dynamics of English language proficiency. Institute of the study of labor (ISA). Discussion papers. Germany.

Creswell, J. W. (1994). Research design: Qualitative \& quantitative approaches. California: Sage.

Devitt, A. J. (1991). Intertextuality in tax accounting: Generic, referential, and functional. In C. Bazerman, \& J. Paradis (Eds.), Textual dynamics of the professions (pp. 336-357). Madison, WI: University of Wisconsin Press.

Eggins, S. (1994). An introduction to systemic functional approach. London: Pinter.

Freedman, A., Adam, C., \& Smart, G. (1994). Wearing suits to class: Simulating genres and simulations as genre. Written Communication, 11(2), 193-226

Foucault, M. (1969). The archaeology of knowledge. New York: Routledge Press.

González Turmo, I. (2004). A methodology for analyzing recipe books. Social Science Information, 43(4), 753-777. https://doi.org/10.1177/0539018404047717

Haggan, M. (2004). Research paper titles in Literature, Linguistics and Science: Dimensions of attraction. Journal of Pragmatics, 3(6), 293-317. https://doi.org/10.1016/S0378-2166(03)00090-0

Halliday, M. A. K. (1994). An Introduction to Functional Grammar. London: Edward Arnold Publishers.

Holmes, R. (1997). Genre analysis and the Social Sciences: An investigation of the structure of research article discussion sections in three disciplines. English for Specific Purposes, 16(4), 321-337. Retrieved from https://doi.org/10.1016/S0889-4906(96)00038-5

Hung, E. (n.d.). Recipe writing: Focus on schematic structure and language features. Retrieved March 1, 2017, from http://www.edb.gov.hk/attachment/../03\%20home\%20economics.pdf

Hyon, S. (1996). Genre in three traditions: Implications for ESL. TESOL Quarterly, 30, 693-722.

Hyland, K. (2004). Genre and second language writing. Ann Arbor, MI: The University of Michigan Press.

Hyland, K., \& Tse, P. (2004). I would like to thank my supervisor: Acknowledgments in Graduate dissertations. International Journal of Applied Linguistics, 14(2), 259-275. https://doi.org/10.1111/j.1473-4192.2004.00062.x

Johns, A. M., Bawarshi, A., Coe, R. M., Hyland, K., Paltridge, B., Reiff, M. J., \& Tardy, C. (2006). Crossing the boundaries of genre studies: Commentaries by experts. Journal of Second Language Writing, 15(3), 234-249.

Karlin, R. F. (1998). Semantic analysis for animation of cooking tasks. Scholarly Commons, 3(1), 23-37. Retrieved March 5, 2017, from http://repository.upenn.edu/cis reports/734 
Klenova, D. (2010). The Language of recipes and cookbooks (Unpublished Dissertation). Department of English and American Studies, Norway.

Kohler, I. (2011). Translating Food: How to translate cultural specific features in Recipes. Modern Linguistics, 3(6), 296-320.

Lin, J., Chris, M., \& Ehud, R. (2002). Style variation in cooking recipes. Heinemann Educational Books.

Lester, J. (2012). A discourse analysis of parents' talk around their children's autism labels. Journal of Disability Studies, 32(4), 110-140. https://doi.org/10.18061/dsq.v32i4.1744

Lewis, K., \& Gregory, M. (2013). Parents' talk to their infants: The importance of context. First Language, 33(4), 23-32.

Mahotra, L., \& Krishnan, G. (2012). An analysis of shopping list apps for Android and iPhone. In Theory and research in HCI. Chicago: Symposium.

Martin, J. R., Christie, F., \& Rothery, J. (1987). Social processes in education: A reply to Sawyer and Watson (and others). In I. Reid (Ed.), The place of genre in learning: Current debates (pp. 46-57). Geelong, Australia: Deakin University Press.

McLaren, Y., \& Calin, G. (2005). Characterizing the genre of the corporate press release. LSP and Professional Communication, 5(1), 10-30.

Miller, C. R. (1984). Genre as social action. Quarterly Journal of Speech, 70(2), 151-167.

Molle, D., \& Prior, P. (2008). Multimodal genre systems in EAP writing pedagogy: Reflecting on a needs analysis. TESOL Quarterly, 42(4), 541-566.

Ofori-Boadu, A. (2003). The Dawn of Cooking: Peace Corps Ghana Nutrition Handbook. Accra: Spec $\begin{array}{lllll}\text { Publishers. } & \text { Retrieved } & \text { January } & \text { 4, 2017, }\end{array}$ http://www.friendsof.ghanaorg/forms/DawnofCooking.pdf

Pamplona-Roger, G. (2012). 250 Recipes for healing and prevention. USA: Safeliz Publishers Team.

Rollins, B. (2009). Introduction to Recipe Writing. New York: Columbia University Press.

Santos, M. B. (1996). The textual organization of research paper abstracts in Applied Linguistics. Journal of Applied Linguistics, 16(4), 481-499. https://doi.org/10.1515/text.1.1996.16.4.481

Stotesbury, H. (2003). Evaluation in research article abstracts in the narrative and hard sciences. Journal of English for Academic Purposes, 2(4), 327-341. https://doi.org/10.1016/S1475-1585(03)00049-3

Sarfo, E. (2011). Offering healthcare through radio: An Analysis of radio health talk by medical doctors. Journal of Language, Discourse \& Society, 1(1), 104-125.

Senda, Y., \& Sinohara, Y. (2000). Analysis of titles and readers-For title generation centered on the readers (Unpublished term paper). Tokyo: Japan

Smart, G. (1993). Genre as community invention: A central bank's response to its executives' expectations as readers. In R. Spilka (Ed.), Writing in the workplace: New research perspectives (pp. 124-140). Carbondale, IL: Southern Illinois University Press. 
Swales, J. M. (1990). Genre analysis: English in academic and research settings. Cambridge: Cambridge University Press.

Swales, J. M., \& Feak, C. B. (2000). English in today's research world: A writing guide. Ann Arbor, MI: The University of Michigan Press.

Swales, J., \& Feak, C. B. (2004). Academic writing for graduate students: A course for non-native speakers of English. Ann Arbor: The University of Michigan Press.

U.S. Department of Health and Human Services. (2009). Keep The Heart Beat: Heart Healthy Recipes. USA: McGraw Publishers.

Yang, A., \& Allison, D. (2003). Research articles in Applied Linguistics: Moving from results to conclusions. English for Specific Purposes, 22(4), 365-385. https://doi.org/10.1016/S0889-4906(02)00026-1 